\title{
CONHECIMENTO EM EDUCAÇÃO: UM OLHAR DESDE O ESTUDO SOBRE REDES DE PESQUISA E COLABORAÇÃO OU OS SAPATOS DA EDUCAÇÃO
}

\author{
DeNISE LeITE*
}

Recebido: 9 jun. 2014

Aprovado: 31 jul. 2014

*Universidade Federal do Rio Grande do Sul. Porto Alegre, RG, Brasil. E-mail: denise.leite@hotmail. com.br

Resumo: Os grupos de pesquisa acadêmicos formam redes que conectam pessoas, instituições, agências, empresas, cujas relações partilhadas em um período de tempo têm a finalidade de produzir conhecimento. Assim, produzir conhecimento em colaboração, escrever e publicar em coautoria são parte das atividades dos pesquisadores que trabalham em redes originadas em um ou mais grupos de pesquisa acadêmicos. Tal atividade vem sendo perscrutada através da análise de redes sociais (ARS), uma área de estudos e uma técnica de investigação, um conjunto de teorias, modelos e aplicações seriamente envolvido com a alteração de padrões nas formas de produzir conhecimentos e consequentemente com as interações e inter-relações que afetam as pessoas ao produzirem conhecimentos em rede. Ao estudar avaliação de redes de pesquisa e colaboração, pesquisa apoiada pelo $\mathrm{CNPq}$, algumas peculiaridades sobre a produção de conhecimento em Educação, vista em contraste com outras áreas de conhecimento, foram detectadas e são apresentadas e discutidas neste texto.

Palavras-chave: Produção de conhecimento. Avaliação. Redes de pesquisa. Educação.

\section{KNOWLEDGE IN EDUCATION: A VIEW FROM THE STUDY OF SCIENTIFIC RESEARCH AND COLLABORATION NETWORKS OR THE SHOES OF EDUCATION}

Abstract: Research academic groups form nets that connect persons, institutions, agencies, enterprises, whose shared relations have the scope to produce knowledge. In that way, to produce knowledge in collaboration, to write and to publish in co-authoship, is a part of researchers' activity when working in nets given rise from one or more academic groups of inquiry. Such an activity was scrutinized through social networks analysis (SNA), an area of studies and a technique of investigation, a set of theories, models and applications seriously wrapped with the alteration of standards in the forms of producing knowledge and consequently with the interactions and inter-relations that affect the persons while producing knowledge in networks. While studying research networks evaluation, inquiry supported by the Brazilian National Council of Research, $\mathrm{CNPQ}$, some peculiarities on the production of knowledge in Education seen in contrast with other areas of knowledge were detected and are presented and discussed in this text.

Key words: Knowledge production. Evaluation. Scientific research networks. Education. 


\section{APRESENTAÇÃO}

É um prazer e uma honra estar neste evento, entre amigos, companheiros de uma trajetória de vida profissional e pessoal. Tenho sentimentos de estar em casa e ao mesmo tempo a sensação de estar em um novo lugar. Peço licença para dizer que me sinto honrada e, ao mesmo tempo, responsabilizada por estar neste lugar apontando e debatendo minhas sapiências e ignorâncias. No conflito dos sentimentos díspares, carrego algumas pretensões. Pretensão de estar a enveredar por um caminho bastante trilhado, o estudo de redes de pesquisa, ao qual pretendo acrescentar minha contribuição; pretensão de, ao chegar atrasada na reflexão sobre redes de pesquisa e colaboração, ainda ter o que dizer.

Valho-me da reflexão de Mia Couto (2005, p. 4), profusamente documentada na internet, para repetir: de onde vem o conflito? Talvez, da dificuldade em assumir fraquezas e fragilidades de minha identidade como educador, assumir que os sapatos andam apertados também para mim. Talvez porque tenho medo de estar a copiar desenhos pré-formatados das maneiras de ser da Educação. Descalçar sapatos que incomodam pode ser um gesto para começar... e, um dos sapatos a descalçar está contido no desafio da proposta deste painel - como se produz conhecimento em rede nesta complexa área de conhecimento que é a Educação? Conhecimento e formação se interpenetram?

De minha parte vou pinçar algumas ideias do que aprendi estudando redes de pesquisa. Convido-vos a descalçar vossos sapatos também, partilhar incertezas, sapiências, dúvidas e ignorâncias.

\section{O PONTO DE PARTIDA: TEMA E CONCEITOS}

O tema produção de conhecimento em Educação surgiu como uma espécie de subproduto de uma pesquisa sobre Avaliação de redes de pesquisa e colaboração (LEITE et al., 2010). Meu ponto de partida, pois, é contar parte desta caminhada.

Quando inicio um trabalho novo, minha primeira tarefa é definir conceitos. Ora, o que é mesmo um grupo de pesquisa? Uma primeira resposta apontaria: grupo de pesquisa é um conjunto de indivíduos organizados para produzir pesquisa. Ou, dizendo de outra maneira, é um conjunto de pessoas que podem se organizar hierarquicamente e compartilhar algo em comum e, nesse sentido, formar uma rede em que pesquisadores mais experientes orientam jovens candidatos à profissão. A rede formada se torna visível quando as pessoas estudam, pesquisam e, também, publicam juntas. Como diz Newman (2001) basta 
que dois cientistas sejam coautores em um texto para que exista uma conexão entre eles, uma rede, enquanto Katz e Martin (1997) falam em rede como trabalho conjunto de dois ou mais cientistas para produzir conhecimento.

Os grupos de pesquisa acadêmicos podem formar redes que conectam pessoas, instituições, agências, empresas, cujas relações partilhadas em um período de tempo têm a finalidade de produzir conhecimento. Assim, produzir conhecimento em colaboração, escrever e publicar em coautoria são parte das atividades dos pesquisadores que trabalham em redes originadas em um ou mais grupos de pesquisa acadêmicos. As atividades se imbricam e as coautorias passam a ser um sinal, uma marca da colaboração, um indicador para estimar as formas de relação entre os cientistas (SOLLA PRICE, 1976; MAIA; CAREGNATO, 2008) e, entre estes e seus parceiros. No entorno da atividade científica, criam-se movimentos de expansão de conhecimento através dos chamados 'colégios invisíveis' (CRANE, 1972), comunidades que trocam informações, pesquisadores que ouvem os professores do sistema, professores do sistema que leem as publicações dos pesquisadores. Tais movimentos evidenciam expansão de redes para além do grupo-célula.

As redes e a interação entre pesquisadores que trabalham em grupos podem ser representadas graficamente por nós conectados, por linhas de conexão, por grafos. A regularidade ou a não linearidade das interações nas redes de pesquisa pode ser visibilizada pois que os grafos permitem 'ver' as estruturas de uma rede, seu componente social de relações. Ora, os cientistas não trabalham a sós em seus laboratórios como durante um mágico tempo acreditamos. A imagem do indivíduo solitário vista em um espaço inacessível aos comuns mortais; o cientista em seu laboratório, com suas provetas e pipetas descobrindo curas e remédios para a humanidade... é coisa de passado místico! Nem aqueles cientistas e também nós os educadores, conseguimos trabalhar como unidades isoladas. Somos parte dos processos, sejam eles da investigação, da avaliação, do ensino. Somos observadores e atores comprometidos e coniventes com os resultados daquilo que produzimos.

Tal atividade vem sendo perscrutada através da análise de redes sociais (CAROLAN, 2014), uma área de estudos e uma técnica de investigação, um conjunto de teorias, modelos e aplicações seriamente envolvido com a alteração de padrões nas formas de produzir conhecimentos, com as interações e interrelações que afetam as pessoas ao produzirem conhecimentos em rede. De tal sorte que a metáfora da 'teia' de conhecimentos se aplicaria à ação de uma rede de pesquisa. E, se ciência é parte do social, pois seus produtos servem à sociedade, as relações entre os cientistas, seus comportamentos e formas de 
interação formam teias e tramas de fios com a ciência que produzem e pela ciência na sociedade em que vivem. São tramas de relações e imbricações de conhecimentos cujos formatos podem ser estudados. De uma forma ampla, e talvez um tanto radical, se pode dizer que a ciência cresce nestas tramas; que ela se estabelece e progride na dependência das redes de colaboração criadas pelos cientistas (NEWMAN, 2001; ADAMS, 2012).

Tal como o docente o faz em sua sala de aula, para cada turma uma nova teia é tecida (FERNANDES, 1999), para cada pesquisa o cientista pode formar uma rede, uma teia diferente. Para cada circunstância, tempo e lugar, uma nova teia de produção de conhecimento também será tecida, por dentro dos grupos de pesquisa, de forma deliberada. Esta metáfora se ajusta aos grupos de investigação institucionais, tais como aqueles registrados junto ao Diretório de Grupos de Pesquisa (DGP) do Conselho Nacional de Desenvolvimento Científico e Tecnológico (CNPq) ${ }^{1}$ Tal como demonstrou Mocelin em 2009 (p. 48), é a partir do grupo de pesquisa, (que) podem ser observadas e acompanhadas as redes de grupos de pesquisa, demonstrando as relações institucionais dos grupos e seu papel no desenvolvimento da pós-graduação no País.

As redes de pesquisa tendem a crescer. Estabelecem-se e desenvolvem-se ao longo do tempo, formam estruturas com laços e vértices, nós e linhas. Os nós e as ligações tendem a aumentar em torno dos pesquisadores principais, dos egos da rede. Os novos elementos da rede, seus atores, gravitam em torno dos mais poderosos, o que faz com que os ricos fiquem mais ricos e os pobres, por vezes, fiquem mais pobres. É o chamado efeito Mateus. A colaboração em ciência, no entanto, parece ser o fenômeno indiscutível desta forma de relações de produção, entendida por vários autores como parte do 'modo 2 de produção de conhecimento' (GIACCOMAZZO, 2014). O "novo", entre aspas, ethos da ciência ${ }^{2}$ (CAREGNATO; MOURA; CAREGNATO, 2012) se identifica no trabalho de colaboração em redes, nas práticas dos pesquisadores das áreas das hard sciences, enquanto nas áreas de Humanidades e Ciências Sociais, as soft sciences, a produção em rede ainda não atingiu seu apogeu.

1 DGB CNPq - O Diretório dos Grupos de Pesquisa no Brasil, projeto desenvolvido no CNPq desde 1992, constitui-se em bases de dados que contêm informações sobre os grupos de pesquisa em atividade no País. As informações contidas nessas bases dizem respeito aos recursos humanos constituintes dos grupos (pesquisadores, estudantes e técnicos), às linhas de pesquisa em andamento, às especialidades do conhecimento, aos setores de aplicação envolvidos, à produção científica e tecnológica e aos padrões de interação com o setor produtivo. Além disso, cada grupo é situado no espaço (região, UF e instituição) e no tempo. In: <http://memoria.cnpq.br/gpesq/apresentacao.htm>. Acesso em: 6 jun. 2014.

2 O tema do processo de transformação nos modos de produzir conhecimento e fazer ciência foi anteriormente desenvolvido, como parte do mesmo projeto que originou este artigo, por Giacomazzo (2014) e por Caregnato e colegas (2012). 
Ao estudar avaliação de redes de pesquisa e colaboração (LEITE et al., 2014) deparei-me com algumas peculiaridades sobre produção de conhecimento em Educação vista em contraste com outras áreas de conhecimento as quais discuto neste texto. Foram os grupos de pesquisa registradas no DGP CNPq que estudei a partir das redes formadas por seus líderes ou egos, pesquisadores 1 A do CNPq, das áreas de Educação, Física e Engenharia da Produção. Suas publicações em coautoria relativas a um período de dez anos, foram submetidas a procedimentos de análise de redes. Dentre os participantes, foram selecionados sujeitos para entrevistas das quais alguns excertos discuto a seguir. O pressuposto, de minha experiência pessoal como líder de grupo, era que as teias de produção de conhecimento em educação se estabeleceriam por dentro dos grupos do DGPB formando redes de coautorias. Conforme as necessidades ou oportunidades visualizadas pelo líder e, talvez também pelos membros do grupo, as redes se intensificariam ao longo do tempo em busca da melhor proposição para produzir, ampliar ou ratificar conhecimentos produzidos em colaboração.

\section{AS REDES: COMO SE FORMAM, AVALIAM E PRODUZEM CONHECIMENTO}

Como se formam e desenvolvem redes de pesquisa e colaboração entre acadêmicos?

Em geral os grupos de pesquisa na Educação surgem depois do doutorado do pesquisador principal ou líder. Os grupos agregam orientandos. Porém, para um dos pesquisadores entrevistados $(1 \mathrm{~A} \mathrm{CNPq}$, líder de grupo de pesquisa há 10 anos), a Educação não trabalharia em rede. Rede no seu entendimento seria a rede de citações, e, neste caso, no seu entender, um produto do elogio fácil, do favorecimento, uma rede mais política do que epistemológica, do tipo 'me cita que eu te cito!' Para outros dentre os entrevistados, haveria uma rede básica e uma rede alargada, ampla, a rede da prática social do pesquisador. Um grupo de pesquisa seria uma forma de rede básica formada pelo pesquisador e seus alunos. A rede alargada seria aquela formada pelo pesquisador e seus leitores, os professores do sistema de educação.

Parece haver nas falas destes pesquisadores uma certa preocupação crítica. Preocupam-se com uma possível rede de citações fáceis que existiria nos contextos da educação e, talvez por isto, não lembram a rede formada pelas coautorias de trabalhos. Nesse caso a rede seria uma aliança para contabilizar produção, uma rede de citações que se formaria para ampliar a circulação científi- 
ca dos trabalhos de pesquisa. Para outros dentre os educadores entrevistados, a rede seria a soma dos trabalhos conjuntos, uma parceria entre pesquisadores e professores das escolas mais os pesquisadores e seus orientandos. A rede não seria visualizada apenas pelas publicações. 'Rede não seria só o que está no Lattes', dizem eles. Parece que intuitivamente conferem o papel de rede aos colégios invisíveis criados a partir da produção do grupo de pesquisa.

Estes posicionamentos diferem de outros. Os pesquisadores da Física (1 A $\mathrm{CNPq}$, líder de grupo de pesquisa há 10 anos), dizem que os grupos de pesquisa se definem pela área de trabalho, especialidade, pela pós-graduação que o físico fez. Em alguns momentos existe cooperação, em outros, os trabalhos podem ser independentes. As redes são formadas a partir de conhecimentos, vínculos, interesses de pesquisa ou para o aprofundamento de problemas. Para alguns entrevistados, as redes foram formadas por iniciativa dos pesquisadores a partir de um doutorado que pode ter sido realizado no exterior e, após a chegada ao Brasil, com os contatos feitos no país estrangeiro. Nesse caso, constroem a rede incluindo os pesquisadores estrangeiros com os quais trabalharam. Os pesquisadores da Engenharia de Produção (1 A CNPq, líder de grupo de pesquisa há 10 anos) entrevistados dizem que os networks em geral são internacionais e se formam com pesquisadores da mesma área de interesse, com colegas, com sociedades, com editores de periódicos. Seria como que 'uma rede sem ideia de formar uma rede' porque a teia de colaboração contempla os vínculos e interesses do pesquisador líder. Contudo, uma vez formada, a rede pode partir de problemas que despertam interesse de empresas, de organizações. Em geral, abrangem e visam resolver problemas de aplicação prática da ciência.

Como deveria ser avaliação dos grupos e redes de pesquisa?

Os pesquisadores da Educação (1 A CNPq, líder de grupo de pesquisa há 10 anos) entrevistados mostram uma crença na reflexão como componente central do processo avaliativo. Para eles a avaliação de redes poderia ser 'um procedimento inaceitável porque seria uma avaliação que consideraria os índices de citação individuais' e as citações podendo ser fraudes, os procedimentos seriam 'não muito bons' porque permitem, e é possível, 'citar apenas os amigos'. Por outro lado, os indicadores que captam citações também incluiriam maus e 'bons procedimentos'.

Dizem que os pesquisadores da Educação precisariam aprender com os 'outros pesquisadores', com aqueles que publicam em periódicos internacionais. Isto seria 'matéria a ser aprendida'. Para os egos líderes de grupos de pesquisa entrevistados, deveria haver indicadores práticos: para artigos, para 
selecionar bibliografia; indicadores condizentes com contextos e condições de cada lugar. Também referem que deveria haver 'chaves' para a avaliação. As chaves certas, os macetes e dicas - tal como no vestibular - deveriam ser conhecidas. Da mesma forma, também seriam conhecidas as chaves para avaliação de artigos e produção de bibliografias.

Quando se referem à avaliação do pesquisador, criticam o 'produtivismo' provocado pela avaliação quantitativa de produtos como as publicações $(\mathrm{Ca}-$ pes). O pesquisador seria produtivo porque 'publicaria $X$ coisas em $X$ período de tempo'. Reafirmam a necessidade de afinar os parâmetros. Sugerem parâmetros qualitativos, ou seja, cada pesquisador apontaria o que é mais relevante da sua produção na área e no período de tempo e por ela seria avaliado.

Estas posições também diferem dos entendimentos dos pesquisadores da Física e da Engenharia de Produção (1 A CNPq, líder de grupo de pesquisa há 10 anos) entrevistados. 'Avaliação direciona a postura', dizem os físicos. Nem sempre numa direção boa, pois, objetiva atender aos parâmetros Capes. Por outro lado, se o pesquisador tem convicção sobre a boa direção (de seu fazer, da sua rede) deve continuar mesmo que não renda mais pontos na avaliação Capes. Acrescentam que, se continuarem os parâmetros produtivistas, não vai haver um prêmio Nobel no Brasil. Para eles o pesquisador tem que ter mais liberdade para sair uma produção original. Isto porque, a escolha dos temas de pesquisa é induzida pelos editais Capes e CNPq o que também direciona a avaliação. Nesse caso, dizem os Engenheiros, a avaliação é uma contrapartida da instituição ou agência de fomento que financia um projeto. Se fornece os recursos, quer um nível de produção, uma produção científica altamente qualificada e, a Avaliação vai dar o feedback para a agência que financiou o grupo e o programa. Quanto aos indicadores Capes, a própria área criou seus indicadores. Considera o Fator de Impacto das revistas e periódicos.

Como se faz a produção de conhecimento nos grupos e redes de pesquisa?

Quatro aspectos se destacam para os pesquisadores da Educação entrevistados, quando se trata de produção de conhecimento: o artesanato intelectual, a inserção da educação no campo social, a imaginação sociológica e as metodologias para fazer o dado existir.

Cada afirmação dos entrevistados se registra a seguir:

- Produção de conhecimento no grupo de pesquisa (educação) é um artesanato intelectual

A produção de conhecimento dentro do grupo, dizem os entrevistados, se faz entre pesquisadores com orientandos e alunos no grupo, é 'um hábi- 
to comum'. Alunos têm que produzir, fazer seu trabalho, 'porque é trabalho, ganham salário, horas, bolsas para isto. Têm que trabalhar duro'. Produção de conhecimento no grupo é para formar o pesquisador. E, o prêmio do pesquisador-líder é formar novos pesquisadores. A produção de conhecimento em educação seria uma 'artesania', um trabalho que pode ter construção coletiva. Porém, reconhecem os entrevistados que essa 'artesania' não é uma construção fácil. É difícil produzir um texto em grupo. No corta, recorta e cola, um texto pode ficar sem pé nem cabeça. Para inovar tem que contrariar a academia e produzir textos pequenos, artesanais (até 4000 caracteres e, não com 15 laudas).

- Conhecimento não tem percurso único. A Educação se insere no campo social que é infinito

$\mathrm{Na}$ Educação, dizem os entrevistados, se consideram as origens do conhecimento uma vez que o campo social é infinito e o conhecimento não faz um percurso único. Pesquisar na educação, para os entrevistados é ir além do que está dado e é conhecido. O conhecimento tem que ter relevância social, ser produzido para a comunidade. A pesquisa é ao mesmo tempo uma prática e um produto do social. Conhecimento se produz para transmitir para o outro, para a realidade da escola, para a comunidade, para os professores das escolas. Os produtos (programa de TV, coleção de livros, filmes, vídeos, revistas, jornais, dvd, cd, jornal, boletins, jogos pedagógicos) são feitos para a realidade da escola e nem sempre servem aos eventos acadêmicos. Porém, estes produtos podem ser a origem para trabalhos acadêmico-científicos para apresentação em congressos e para publicação de artigos. Os entrevistados consideram que há uma dupla conversão do texto. Nesta perspectiva os trabalhos publicados são para o público do país porque "o estrangeiro não pode pensar a prática social do país".

- Produzir conhecimento é lidar com a 'Imaginação sociológica'3 para buscar os problemas, para descobrir aquilo que tem que ser desbravado.

Os problemas de pesquisa surgem, então, da "imaginação sociológica", na 'sintonia com aquilo que cega, que não se sabe ainda, com o que tem que ser desbravado'! O pesquisador encontra os problemas de pesquisa a partir da leitura de um livro, do levantamento de questões relativas a estudos em curso, da pesquisa anterior finalizada, das perguntas dos alunos, da interação e da

3 Sociological imagination - Charles Wright Mills criou a expressão em 1959 ao referir a interação entre o ser individual e o social; o cotidiano, as instituições sociais e o lugar do sujeito na história. Ver: <http://sociologiacienciaevida.uol.com.br/ESSO/Edicoes/46/artigo288591-1.asp dentre outros>. 
troca, mesmo que informal, com outros pesquisadores, em congressos e outros, do contato com os professores das escolas. Pesquisar para os educadores é ir além do que está dado e é conhecido, é entender a educação como uma prática do social. É a consideração do social que dá relevância à produção de conhecimento em educação. A imaginação sociológica favorece o trabalho com o cotidiano das escolas, dos docentes.

- Metodologias importam para fazer o dado emergir, existir!

$\mathrm{Na}$ educação o pesquisador não coleta o dado. O dado marca a pesquisa e precisa ser produzido, buscado, porque ele não existe por si. A maneira, o caminho percorrido para chegar ao dado faz com que este dado exista. Daí a importância da metodologia para a produção de conhecimento.

Em contraste a estas posições dos educadores entrevistados e, de forma resumida, reproduzo alguns dentre os elementos que caracterizam a produção de conhecimento na Física e na Engenharia da Produção. Para os Físicos os problemas de pesquisa surgem a partir de suposições ou teorias ou resultados experimentais. É preciso analisar, encontrar falta de clareza, lançar os 'cachorros perdigueiros' atrás do problema. Tal complexidade, gera o que eles referem como 'as torturas lentas da expressão ou a arte de produzir conhecimento em Física'. Significa usar instrumentos, usar as mãos; observar a dinâmica dos resultados iniciais; examinar o que não está coerente, compatível. O interesse é o progresso do conhecimento. Envolve relacionar o achado experimental com a teoria, interpretar resultados, explicar ou achar erros e entender o fato dentro de teorias consolidadas e, também, descobrir fenômenos novos ou descobrir causas de fenômenos conhecidos. Há uma visão integrada do conhecimento na Física, dizem os entrevistados. Físicos teóricos e físicos experimentais, acrescentam, podem trabalhar juntos: ideias teóricas levam físicos experimentais a pensar em experiências com os resultados que elas trazem e às vezes não compreendem os porquês. É preciso explicar o que acontece e, por isto, um físico experimental também desenvolve teoria. A cooperação científica é um projeto comum - cada um faz a sua parte, alguém é o integrador, em geral o líder do grupo. O trabalho tem que ser de todos (tem muita disputa, inveja). A produção de conhecimento se gera em redes.

Para os Engenheiros entrevistados, pesquisar é gerar o conhecimento do futuro, o conhecimento estratégico. O conhecimento se gera sob análise de situação, simulação e ajustes de modelos anteriores. Consideram-se históricos de comportamento dos últimos anos - fazem-se simulações e criam-se cenários possíveis. Dentre estes cenários, se estuda a possibilidade mais otimista 
e a mais pessimista até chegar ao conhecimento estratégico, o new way, o programa montado, a "magia das previsões". O conhecimento se gera em parcerias, em redes de grupos heterogêneos que incluem empresas. Os problemas são reais, concretos. E, dizem os entrevistados, a produção de conhecimento recebe incentivo, tanto das agências, quanto das empresas e das avaliações. Os incentivos são para produzir conhecimentos e publicações. Os incentivos também são financeiros (um grupo pode receber de $\$ 4$ a 5 milhões de reais para produzir conhecimento sobre um problema dado). Os engenheiros entrevistados referem que selecionam problemas para os quais as agências e empresas dão incentivos financeiros. Dedicam-se a projetos de produção de conhecimento publicável nos veículos que têm peso em avaliação (preocupação com os indicadores de avaliação). Projetos que qualificam, diferenciam. Trabalham com os notórios da área. Trabalham em redes.

Em resumo, ao contrastar as falas dos pesquisadores de excelência classificados como $1 \mathrm{~A} \mathrm{CNPq}$, sobre a formação de seus grupos de pesquisa, sobre a forma como entendem a avaliação dos grupos e redes que lideram, sobre a forma como produzem conhecimento nos seus grupos de pesquisa, sou compelida a aceitar que o ethos da produção de conhecimento na Educação continua a ser vivido e praticado de forma tradicional. Nossas peculiaridades quando postas em pauta e comparadas a duas áreas de conhecimento cuja produção é notória, mostram que não estamos vivendo um novo ethos da pesquisa. Caso minhas 'ignorâncias' dedutivas façam sentido minha percepção neste momento é que - me incluo como parte - nós, pesquisadores da Educação, temos sapatos a descalçar, alguns sapatos de salto alto!

\section{OS SAPATOS DA EDUCAÇÃO OU COMO APRENDER COM MIA COUTO E REFLETIR SOBRE CONHECIMENTO EM EDUCAÇÃO}

Os pesquisadores estão convictos de que a Educação é diferente das outras áreas porque trabalha com a prática social. Lideram grupos de pesquisa que produzem conhecimento sobre e para as escolas. Dizem com tranquilidade que as normas para produzir um texto são menos exigentes do que para um evento. Entendem que a produção do conhecimento tem que ser avaliada, mas, a avaliação da Capes dá como subproduto o 'produtivismo' individual! Entendem que a produção internacional na educação se torna impensável porque um estrangeiro não pode pensar a prática social daqui; o estrangeiro só quer saber o que fazemos aqui (e talvez, copiar). Acrescentam ainda que ir a congresso não é inserção internacional, é turismo acadêmico! 
A relevância social da produção em Educação se traduz em transmitir conhecimento para o outro, para as comunidades. Fazer pesquisa se justifica como prática e produto social. A Educação pensa cientificamente a escola. Produz textos (para escolas) sobre preocupações teórico-metodológicas. Trabalhar com a realidade da escola confere relevância social à produção de conhecimento. Haveria um equívoco social a suprir - a desvalorização do professor em favor da valorização do pesquisador.

Por outro lado, os pesquisadores entrevistados dizem que à Educação faltam chaves (certas) das portas. Chaves que servem para avaliar um artigo (bom/mau/ruim), avaliar um periódico (índices de citação), para selecionar uma bibliografia (certo/errado). O pesquisador não faz alianças para ter mais citações; tratar bem um pesquisador para produzir com ele seria moralmente inaceitável. Existe o certo e o errado, o bom e o mau conhecimento. O 'produtivismo' seria resultado de um mau uso da avaliação. Apontam que a avaliação com aferição dos índices de citação (produtividade), seria procedimento 'não' bom. Lembram a questão de citar amigos, por exemplo. A rede de citação seria um produto do elogio fácil, do favorecimento, mais política do que epistemológica (me cita que eu te cito!). Lembram que hierarquizar pela avaliação é penalizar. A meu ver, e isto não foi dito, consideram que a avaliação na Educação é um procedimento que inclui uma perspectiva moralista antes do que uma perspectiva técnica ou de accountability.

$\mathrm{O}$ 'produtivismo' na Educação seria um subproduto da avaliação (Capes). Traduz-se em estereótipos como: - Dize-me onde publicas e te direi quem és; -Dize-me com quem publicas e te direi aonde chegarás; - o produtivismo só atingiria as novas gerações, os antigos pesquisadores não se deixariam atingir; -publicar por publicar/publicar ou morrer; - publicação, se tornaria um fim -publicar X coisas em X período de tempo é ser produtivo!

Enfatizam que escrever em Educação é trabalho artesanal (semelhante ao do filósofo). Não tem parâmetros. Contudo, é difícil produzir texto em grupo porque o orientando (aluno) faz recorte de um, de outro e o texto fica sem pé nem cabeça. Além disso, publicar por publicar seria produzir mau conhecimento.

Os pesquisadores entrevistados criticam o fato de que pesquisador tem que ter grupo de pesquisa por que: - sai do doutorado e cria grupo de pesquisa; Pós-graduação nacional vira um necrotério - vira doutor e morre; - 70\% dos pesquisadores não seriam pesquisadores (verdadeiros).

Observo que essas e outras considerações, apontadas pelos entrevistados nesse estudo, talvez resumam algumas dentre as formas de pensar de pesqui- 
sadores a respeito da produção de conhecimento em Educação. Seriam 'naturalizados', pensares de senso comum. Talvez sejam de uso corrente no meio científico universitário onde se produz a ciência acadêmica do país. Tais pensares apontam, pelo menos, três sapatos apertados da Educação.

\section{Primeiro sapato}

Educação é diferente das outras áreas porque trabalha com a prática social.

Toda ciência é social, todo produto da ciência em maior ou menor medida tem a ver com a sociedade, dela se origina e para ela vai voltar. Portanto, os mesmos pesquisadores que dizem ser a pesquisa em Educação justificada em sua relevância por ser uma prática voltada para o social, não veem as demais ciências que estão ao seu lado.

Educação não é diferente!

\section{Segundo sapato}

Educação pensa cientificamente a escola.

Pensar a escola é parte da produção do conhecimento em Educação. Não é porque o pesquisador da Educação pensa sobre a escola que o pensar se faça cientificamente. A produção de conhecimento em Educação é mais do que a escola, ela vai à universidade, ao gestor, ela atinge os mais diferentes recônditos da relação humana do aprender e do ensinar nas suas especificidades, especialidades, profundidades e inovações.

Depois, pensar cientificamente a escola de modo isolado, sem outras ciências seria uma tarefa inalcançável. Veja-se o que dizem os pesquisadores da Física, a cooperação científica é um projeto comum. O Físico pensa com o matemático, o economista, o programador, o neurocientista... o Físico experimental com o Físico teórico.

\section{Terceiro sapato}

Educação não detém as chaves (certas) das portas da avaliação

Seria um contrassenso dizer que não temos as chaves das portas da avaliação. Ocorre que a pesquisa em avaliação em nosso país é insuficiente; os métodos quantitativos de pesquisa são desestimulados a priori porque os pesquisadores não dominam as técnicas e metodologias quantitativas e a avaliação (como da Capes) exige tal domínio. Infelizmente, como aponta Mia Couto, nos conduzimos como clientes, como consumidores, mais do que como produtores e sujeitos da história. Portanto é mais fácil criticar e colocar a culpa em outro/s (Capes, CNPq, pesquisadores das hard sciences, editores dos jour- 
nals internacionais) que teriam as chaves 'certas', ou seja, chaves que não temos e que vemos nas mãos de inimigos.

\section{OS SAPATOS APERTADOS E AS PROVOCAÇÕES PARA CONCLUIR SEM CHEGAR AO FINAL}

Descalçar sapatos apertados significa colocar os pés no chão. Para concluir sem ter chegado ao final das reflexões que aqui expus, diria que o estudo sobre redes de pesquisa e colaboração me fez pensar que as redes e grupos reproduzem relações de poder, maneiras de pensar e entender o mundo, me mostraram alguns dos meus limites.

As maneiras de entender a produção de conhecimento nos grupos de pesquisa, nas redes formadas por dentro dos mesmos, parecem críticas. Primeiro, a educação não é diferente no sentido da ênfase em uma cientificidade própria porque trabalha com a prática social. Outras ciências também o fazem. Não é privilégio da Educação. Depois, as maneiras de trabalhar em isolamento, sem parcerias, de criticar as redes porque elas podem ser apenas de citações, retiram da pesquisa o sentido da colaboração, decididamente o componente central dos modos de fazer ciência na contemporaneidade. Talvez uma 'certa' humildade ajude na aproximação com os outros para pedir ajuda e trabalhar em conjunto, aprender com eles, formar parcerias. Armar teias de produção de conhecimento cujos laços ultrapassem as próprias fronteiras e limitações antes do que as fronteiras do país, pode ser um belo empreendimento.

Por outro lado, cabe refletir sobre uma ideia bastante específica: citar amigos e ampliar a rede de citações. Nesse caso, diria que a interlocução se restringe porque se torna mais fácil pesquisar e escrever para poucos, ainda que se obtenha repercussão limitada, muitas vezes apenas dos próprios orientandos ou ex-orientandos, e, às vezes, nem desses. Sem articular aquilo que se discute com argumentos externos apresentados por outros cientistas, de outras áreas de conhecimento ou lugares e contextos, a cientificidade ficaria também restrita, resguardada apenas pelos princípios teóricos ou citação de um ou outro autor estrangeiro ou nacional aceito pela área. Diferente do procedimento sugerido pelos físicos que parecem se comunicar amplamente; que não ignoram o argumento de visões opostas mesmo que distantes teoricamente, antes as consideram como necessárias ao progresso do conhecimento. As ciências humanas e sociais, por seu objeto complexo e subjetivo; por discutir problemas localizados (porque sempre se trata de ambiente empírico singular) propiciam condições para a 'fala', a citação entre irmãos ou amigos, algo como 
uma igreja. Se as ciências naturais não estão isentas desse subterfúgio, são as ciências humanas e sociais que parecem estar mais expostas a esse risco. Há temor em expor-se ou em expor ideias que podem ser rejeitadas por argumentos de um parecer anônimo? Esconde-se nessa especificidade o problema da ausência de uma linguagem universal para a área da educação?

Por outro lado produzir conhecimento em clima de culpabilização dos outros - os 'outros' seriam a Capes, as comissões julgadoras e avaliadoras de livros, revistas, projetos - não leva a lugar algum. Se os outros são, também, as ciências duras e aplicadas que 'sabem' publicar internacionalmente e impõem seus parâmetros de cientificidade, à Educação mais vale espreitar e aprender. E, se a avaliação toma a embalagem pelo conteúdo, a aparência e a quantidade de produtos - publicações e bibliografias que muitas vezes ninguém leu - pelos processos formadores que realmente realiza a Educação, então, esta avaliação não diz o que a Educação faz e, portanto não serve. Também não serve apontar falhas morais na avaliação, afinal, ela é apenas um 'organizador qualificado'. Como tal, a avaliação está aí para ser estudada, ela é parte da competência, do saber científico do educador.

De minha parte entendo que as redes formadas nos grupos de pesquisa podem estender a produção de conhecimento em Educação. Entendo também que não faltam chaves para produzir conhecimento. Até porque, o pesquisador tanto da Educação quanto de outras áreas, para além de produzir conhecimento, tem o papel de colocar em funcionamento em seus grupos e redes, uma 'fábrica de cidadania ativa'. Como pretende esse encontro, e se firma no folder que o apresenta - em conexão se constroem 'ideias e ideais de autonomia, equidade, desenvolvimento intelectual, moralidade e cidadania’!

De minha parte entendo, com Mia Couto, que mais vale descalçar sapatos, andar descalço, do que tropeçar com os sapatos dos outros.

\section{REFERÊNCIAS}

ADAMS, Jonathan. The rise of research networks. Nature, London, v. 490, p. 335-336, out. 2012.

CAREGNATO, Célia Elizabete; MOURA, Ana Maria Mielniczuk; CAREGNATO, Sônia Elisa. Ciência em contextos: ethos acadêmicocientífico e dinâmica da pesquisa registrada no CNPq. In: LEITE, Denise; LIMA, Elizeth Gonzaga dos Santos (Orgs.). Conhecimento, avaliação e redes de colaboração. Produção e produtividade na universidade. Porto Alegre: Sulina, 2012. 
CAROLAN, Brian V. Social network analysis and education. Theory, methods \& applications. Thousand Oaks, Ca.: Sage Publications, 2014.

COUTO, Mia. Os sete sapatos sujos. Oração de sapiência por Mia Couto.

Maputo, Moçambique: Universidade Eduardo Mondlane, 2005. Disponível em: <http://www.macua.org/miacouto/MiaCoutoISCTEM2005.htm>. Acesso em: 4 jun. 2014.

CRANE, D. Invisible colleges: diffusion of knowledge in scientific communities. Chicago, University of Chicago Press, 1972.

FERNANDES, Cleoni Maria. Sala de aula universitária: ruptura, memória educativa, territorialidade. O desafio da construção pedagógica do conhecimento. Tese (Doutorado em Educação) - Programa de PósGraduação em Educação da Universidade Federal do Rio Grande do Sul. Porto Alegre: UFRGS, 1999.

GIACOMAZZO, Graziela. Ciência modo 2 e o ensino nas universidades do Século XXI: a dinâmica das redes e da educação a distância. Tese (Doutorado em Educação) - Programa de Pós-Graduação em Educação da Universidade Federal do Rio Grande do Sul. Porto Alegre: UFRGS, 2014.

KATZ, Silvan; MARTIN, Ben R. What is research collaboration? Research Policy, North Carolina, v. 26, p.1-18, 1997.

LEITE, Denise et al. Avaliação de redes de pesquisa e colaboração: inovação e mudanças nas teias do conhecimento. Porto Alegre: Ufrgs CNPq, 2010. Projeto de pesquisa.

LEITE, Denise; CAREGNATO, Célia Elizabete; LIMA, Elizeth Gonzaga dos Santos; PINHO, Isabel; MIORANDO, Bernardo Sfredo; SILVEIRA, Priscila Bier. Avaliação de redes de pesquisa e colaboração. Avaliação, Campinas; Sorocaba, SP, v. 19, n. 1, p. 291-312, mar. 2014.

MAIA, Maria de Fátima Santos; CAREGNATO, Sônia Elisa. Coautoria como indicador de redes de colaboração científica. Perspectivas em Ciência da Informação, Belo Horizonte, v. 13, p. 18-31, 2008.

MOCELIN, Daniel Gustavo. Concorrência e aliança entre pesquisadores: reflexões acerca da expansão de grupos de pesquisa dos anos 1990 aos 2000 no Brasil. Revista Brasileira da Pós-Graduação, Brasília, v. 6, n. 11, p. 35 - 64, dez. 2009. 
NEWMAN, M. E. J. The structure of scientific collaboration networks.

Proceedings of the National Academy of Sciences of the United States of America, Santa Fe, v. 98, n. 2, p. 404-409, 2001.

SOLLA PRICE, Derek. Networks of Scientific Papers. Science Magazine, New York, v. 149, n. 3683, p. 510-515, 1976.

\section{NOTA DE AGRADECIMENTO:}

Este trabalho em sua versão final contou com a revisão da Dra. Célia Elizabeth Caregnato e da Dra. Ana Maria e Souza Braga. Algumas ideias apresentadas foram alvo de análise e debate entre pesquisadores e estudantes do Grupo InovAval. O texto resulta igualmente das discussões com participantes de diferentes eventos nos quais a pesquisa que lhe deu origem foi relatada. Sou imensamente grata pela colaboração irrestrita oferecida por todos e todas e pelas sugestões recebidas. 